\title{
Evaluating a New Deposition Velocity Module in the Noah Land-Surface Model
}

\author{
U. Charusombat - D. Niyogi - A. Kumar - X. Wang • \\ F. Chen - A. Guenther - A. Turnipseed · K. Alapaty
}

Received: 7 June 2009 / Accepted: 15 July 2010 / Published online: 4 August 2010

(C) Springer Science+Business Media B.V. 2010

\begin{abstract}
The community Noah land-surface model (Noah LSM) has been modified to couple with a photosynthesis-transpiration scheme (GEM) to estimate the deposition velocity $\left(V_{d}\right)$ for air quality studies. This new capability of the Noah-GEM model was tested in a point version of the National Center for Atmospheric Research-High Resolution Land Data Assimilation System (HRLDAS). Ozone $V_{d}$ observations from June 1-30, 2002 over the AmeriFlux forested site located at Niwot Ridge, Colorado, USA $\left(40^{\circ} 1^{\prime} 58^{\prime \prime} \mathrm{N} ; 105^{\circ} 32^{\prime} 47^{\prime \prime} \mathrm{W}\right)$ were used. The model reasonably captures $V_{d}$ variations for both dry and wet conditions but has problems at nighttime. Experiments were performed to assess the sensitivity of $V_{d}$ calculations to surface characteristics related to vegetation and soil parameters. The results indicated that $V_{d}$ values are sensitive to accurate specifications of the leaf area index (LAI) and a lesser extent to vegetation type, maximum stomatal resistance $\left(R_{\text {smax }}\right)$ and soil texture prescription. The model sensitivity to canopy resistance was noted for both daytime and nighttime. For this forest site, neither soil textures nor soil moisture appeared to affect $V_{d}$ calculations significantly, though they affected the surface heat-flux estimation particularly under low soil moisture conditions. Therefore, the $V_{d}$ estimation in the Noah model can be enhanced by either site-specific LAI or assimilating regional normal difference vegetation index information for specific time periods. Results also highlighted the need to lower the current constant $R_{\text {smax }}$ value used in Noah and other land-surface models.
\end{abstract}

U. Charusombat · D. Niyogi $(\bowtie)$

Purdue University, West Lafayette, IN 47907, USA

e-mail: climate@purdue.edu

A. Kumar · X. Wang · F. Chen · A. Guenther - A. Turnipseed

National Center for Atmospheric Research, Boulder, CO 80307, USA

X. Wang

Sun Yat-Sen University, Guangzhou, China

K. Alapaty

DOE Atmospheric Radiation Measurement Program, Germantown, MD, USA 
Keywords Air quality - Deposition velocity · Land data assimilation system ·

Noah land-surface model

\section{Introduction}

Regional models such as the Weather Research and Forecasting (WRF) model are widely applied for environmental and regional climate studies; WRF is also used for both operational weather and air quality forecasting (Grell et al. 2005). Land-surface models (LSM) such as the Noah LSM (Chen and Dudhia 2001; Ek et al. 2003) have been primarily used to develop realistic surface energy and water fluxes as surface boundary conditions for the WRF model. The land surface is also important as a sink for atmospheric pollutants through deposition pathways (Garland et al. 1974; Niyogi et al. 2003). In this paper, we discuss the development of a new capability for the Noah LSM, which will provide air-pollutant deposition velocity $\left(V_{d}\right)$ estimates by coupling the Noah LSM with a photosynthesis-based canopy resistance formulation, referred to as the gas exchange evapotranspiration model (GEM).

Early understanding of $V_{d}$ estimates was principally driven by field measurements and the synthesis of aerodynamic resistance $\left(R_{a}\right)$, the boundary-layer resistance $\left(R_{b}\right)$, and canopy resistance $\left(R_{c}\right)$ (Garland et al. 1974; Wesely and Hicks 1977). Hicks et al. (1985) and Baldocchi et al. (1987) developed a resistance-based model to calculate $V_{d}$, and an enhancement of that modelling approach was adopted to include a multilayer model (MLM, Meyers et al. 1998; Cooter and Schwede 2000) to develop $V_{d}$ estimates over the USA as part of the Clean Air Status and Trends Network (CASTNet) established by the US Environmental Protection Agency (EPA). While a number of other $V_{d}$ model options exist (e.g. Erisman et al. 1994; Pleim et al. 2001; Zhang et al. 2003; Niyogi et al. 2003; Wu et al. 2009), this addition is used in developing a $V_{d}$ module within Noah so as to use parts of these models to improve the description of atmosphere/land-surface interactions and to allow for gas exchange (particularly $\mathrm{CO}_{2}$ ) fluxes in the coupled WRF-Chem/Noah model. Thus, the broader objective is to eventually develop capabilities for incorporating integrated environmental, hydrological, and surface energy balance/ $\mathrm{CO}_{2}$ flux studies using the Noah LSM as part of a land data assimilation system (Chen et al. 2007) or coupled WRF-Chem model. The existing option, Jarvis-type evapotranspiration schemes in the Noah LSM, does not have $\mathrm{CO}_{2}$ interaction terms, and is heavily dependent on the minimum canopy resistance $\left(R_{c m i n}\right)$ specifications (Niyogi and Raman 1997; Niyogi et al. 2009). The evolving framework is being developed within the US National Science Foundation's BEACHON (Bio-hydro-atmosphere interactions of energy, aerosols, carbon, $\mathrm{H}_{2} \mathrm{O}$, and organics and nitrogen) initiative. Under the BEACHON framework, the Noah model is being modified to include the GEM canopy resistance scheme, which will then be linked with the model of emissions of gases and aerosols from nature (MEGAN) biogenic emission (Muller et al. 2008). These models will be fully integrated with the Noah LSM within the regional High Resolution Land Data Assimilation System (HRLDAS, Chen et al. 2007), WRF, and WRF-Chem. Thus, the ability of the Noah-GEM-HRLDAS framework to estimate $V_{d}$ is of broad interest, and is the focus of this study.

The GEM-HRLDAS coupling has been discussed in Kumar et al. (2008), and the proof of concept tests for using GEM in air quality and land-surface studies has been reported in Niyogi et al. (2003, 2006) and Niyogi et al. (2006). Niyogi et al. (2009) developed and coupled the GEM to an atmospheric boundary-layer model and tested it over different landscapes. The photosynthesis-transpiration/stomatal resistance scheme showed good performance over different vegetation types. However, due to the big leaf approach used in the model, additional tests over forest canopies and heterogeneous soil moisture conditions are desired. The main 
objectives of this study are, (i) to assess the performance of the Noah-GEM-HRLDAS model framework in calculating $V_{d}$ over a forest site, and (ii) to assess the sensitivity of surface characteristics when calculating $V_{d}$.

In the following section, we discuss the experimental framework for the modelling experiments and the observational set-up. Section 3 presents the model results. The discussion first focuses on the performance of the modelling framework over the study site, while the subsequent discussion focuses on the sensitivity analysis of the model results to surface variables using different statistical approaches. Section 4 summarizes the conclusions.

\section{Models and Site Description}

\subsection{Modelling Analysis}

The Noah-GEM-HRLDAS was configured over the Niwot Ridge study site in Colorado, USA and initialized with static land use and soil texture fields as well as time-varying meteorological forcing fields. Single grid forcing data were created for the study period with 18 months of spin up from 1 Jan 2001-30 June 2002. Hourly meteorological forcing fields such as air temperature, surface mixing ratio, wind velocity components, and downward shortwave and longwave radiation fluxes were developed from the tower observations as input to the Noah model. For the 18-month period, precipitation fields were obtained from 4-km hourly NCEP (National Center for Environmental Prediction) stage-IV rainfall analysis, which is based on rain gage-calibrated WSR-88D radar (Weather Surveillance Radar 88 Doppler) rainfall estimates (Fulton et al. 1998). These calibrated rainfall fields over the Niwot site were morphed with onsite precipitation. The model was run as a single point HRLDAS system to develop offline estimates of $V_{d}$. The model calculates $V_{d}$ as the inverse of the sum of the three resistance terms: $R_{a}, R_{b}$, and $R_{c}$. Different formulations can be used for estimating $R_{a}$, consequently we estimated $R_{a}$ using onsite wind observations and the empirical approach of Lui et al. (2007). The $R_{b}$ and $R_{c}$ terms are computed in Noah-GEM following the photosynthesis approach (Niyogi et al. 2003, 2006); details of these formulations are given as Eqs. 8, 9, 10, and 11 in Appendix A. The model was run in a default mode with standard Noah and GEM parameters values. To assess the sensitivity of vegetation and soil parameters in the $V_{d}$ estimation, 112 ensemble runs were performed (Table 1). Model results were analysed for changes in mean and diurnal patterns using time series and descriptive statistics. Furthermore, results were analysed to assess the impact of surface parameters on the $V_{d}$ estimates using interaction explicit factorial analysis (Niyogi et al. 1999). The degree of agreement $(d)$ and fractional bias $(F B)$ between observation and model results were calculated using

$$
\begin{gathered}
d=1-\sum_{i=1}^{n}\left(o_{i}-m_{i}\right)^{2} / \sum_{i=1}^{n}\left(\left|o_{i}\right|+\left|m_{i}\right|\right)^{2}, \\
F B=2\left(\frac{\sum_{i=1}^{n} o_{i}}{n}-\frac{\sum_{i=1}^{n} m_{i}}{n}\right) /\left(\frac{\sum_{i=1}^{n} o_{i}}{n}+\frac{\sum_{i=1}^{n} m_{i}}{n}\right),
\end{gathered}
$$

where $o_{i}$ is the observation, $m_{i}$ is the model result, and $n$ is the number of samples.

The periods of 7-12 June and 23-30 June 2002, which featured wet and subsequently dry soil conditions, are the focus of this paper. For 7-12 June 2002, the average soil moisture content was $15 \%$ due to $35 \mathrm{~mm}$ of accumulated precipitation during 3-5 June 2002. For 23-30 
Table 1 Summary of experiments

\begin{tabular}{|c|c|c|}
\hline Experiment & Variable & Values \\
\hline \multicolumn{3}{|c|}{ Vegetation parameters } \\
\hline $1-4$ & Vegetation types & $\begin{array}{l}\text { Deciduous needle leaf forest: } 12 \\
\text { Evergreen broad leaf forest: } 13 \\
\text { Evergreen needle leaf forest: } 14 \\
\text { Mixed forest: } 15\end{array}$ \\
\hline $5-10$ & Leaf area index & $1,2,3,4,5,6$ \\
\hline $11-15$ & Green vegetation fraction & $0.5,0.6,0.7,0.8,0.9$ \\
\hline $16-20$ & Maximum stomatal resistance $\left(\mathrm{s} \mathrm{m}^{-1}\right)$ & $1,000,2,000,3,000,5,000,7,500$ \\
\hline \multicolumn{3}{|l|}{ Soil textures } \\
\hline $21-32$ & Texture & $\begin{array}{l}\text { Sand, loamy sand, sandy loam, silt } \\
\text { loam, silt, loam, sandy clay loam, } \\
\text { silty clay loam, clay loam, sandy } \\
\text { clay, silty clay, and clay. }\end{array}$ \\
\hline \multicolumn{3}{|c|}{ Soil properties } \\
\hline $33-40$ & Hydraulic function & $\pm 10 \%, \pm 25 \%, \pm 50 \%, \pm 100 \%$ \\
\hline $41-48$ & Saturated soil metric potential & $\pm 10 \%, \pm 25 \%, \pm 50 \%, \pm 100 \%$ \\
\hline $49-56$ & Albedo & $\pm 10 \%, \pm 25 \%, \pm 50 \%, \pm 100 \%$ \\
\hline $57-64$ & Roughness length & $\pm 10 \%, \pm 25 \%, \pm 50 \%, \pm 100 \%$ \\
\hline $65-72$ & Dry soil moisture content & $\pm 10 \%, \pm 25 \%, \pm 50 \%, \pm 100 \%$ \\
\hline $73-80$ & Maximum soil moisture content & $\pm 10 \%, \pm 25 \%, \pm 50 \%, \pm 100 \%$ \\
\hline $81-88$ & Reference soil moisture content & $\pm 10 \%, \pm 25 \%, \pm 50 \%, \pm 100 \%$ \\
\hline $89-96$ & Soil hydraulic conductivity & $\pm 10 \%, \pm 25 \%, \pm 50 \%, \pm 100 \%$ \\
\hline 97-104 & Saturated soil water diffusivity & $\pm 10 \%, \pm 25 \%, \pm 50 \%, \pm 100 \%$ \\
\hline $103-112$ & Quartz content & $\pm 10 \%, \pm 25 \%, \pm 50 \%, \pm 100 \%$ \\
\hline
\end{tabular}

June 2002, the accumulated precipitation was $6 \mathrm{~mm}$ with the average soil moisture content of $8.8 \%$. Figure 1 shows the time series of observed precipitation, soil moisture, and $V_{d}$ values for June 2002. According to Turnipseed et al. (2009), the $V_{d}$ values generally increased after rainfall due to chemical reactions on the leaf surface.

\subsection{The Niwot Ridge Site}

The Niwot Ridge AmeriFlux site $\left(40^{\circ} 1^{\prime} 58^{\prime \prime} \mathrm{N} ; 105^{\circ} 32^{\prime} 47^{\prime \prime} \mathrm{W}\right)$ is located in the Roosevelt National Forest in the Rocky Mountains of Colorado, USA and is dominated by a subalpine forest with an abundance of Lodgepole pine, Engelmann spruce, and subalpine fir (Turnipseed et al. 2009). The study period for the $V_{d}$ analysis was June 2002 because of the higher summer time ozone concentrations over the study region. The site has peak ozone concentrations when the upslope flow carries pollutants from the Denver metropolitan area, which typically occurs during the late afternoon and early evening periods. Turnipseed et al. (2006, 2009) characterized the Niwot Ridge site with a leaf area index (LAI) of 4.2 and roughness length of $1.6 \mathrm{~m}$; the typical canopy height is $11.4 \mathrm{~m}$ and displacement height is $7.8 \mathrm{~m}$.

The Niwot Ridge site is an active AmeriFlux site and has a variety of instruments to estimate surface atmosphere exchanges. Data are typically available at 15-min or 30-min intervals; as a result, the deposition velocities $\left(V_{d}\right)$ were estimated as a ratio of deposition flux and 


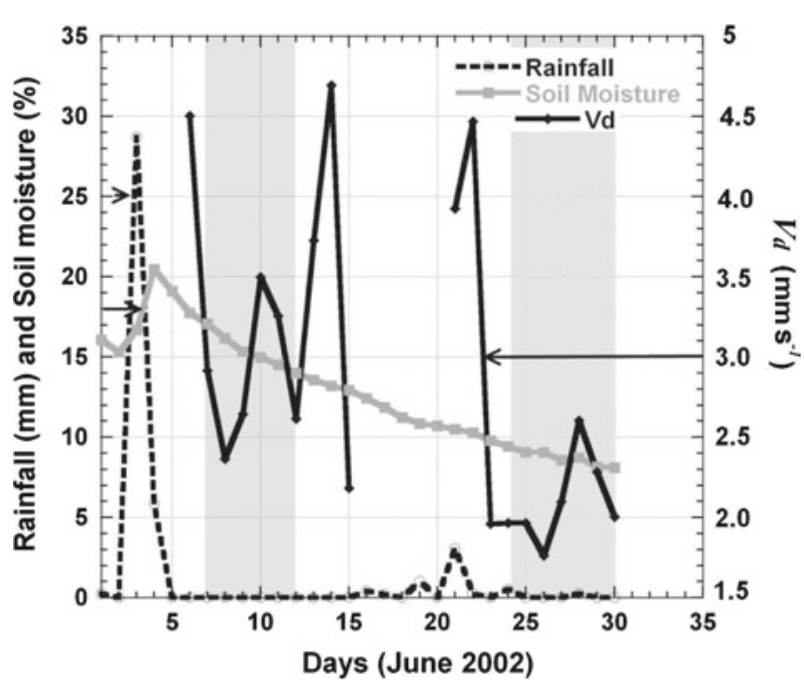

Fig. 1 Observed rainfall, percent of soil moisture at $0.01 \mathrm{~m}$, and dry deposition velocity, $V_{d}$, during June 2002. The shaded boxes correspond to the "wet" and "dry" periods analysed in the study

gas concentration. The fluxes were calculated using the eddy-covariance technique, and gas concentrations were measured by an ultraviolet absorption ozone monitor (Turnipseed et al. 2009). Other parametric values, particularly the resistance terms used for model comparison, are calculated using onsite meteorological and $V_{d}$ observations along with the back calculation of aerodynamic and boundary-layer resistances following Hicks et al. (1987). Additionally, the canopy resistance was calculated using a Penman-Monteith resistance formulation (Turnipseed et al. 2003; Alfieri et al. 2008 also see Lamaud et al. 2002). Other micrometeorological quantities (radiation fluxes, surface meteorology, and soil parameters/variables) required for driving the offline HRLDAS (Chen et al. 2007) were compiled from onsite observations.

\section{Results and Discussion}

Study results are presented in five sections. First, the comparison of the Noah-GEM-HRLDAS model results with field observations is discussed, which is followed by an ensemble analysis of the sensitivity of $V_{d}$ to different surface parameters. The sensitivity of $V_{d}$ estimation is further discussed using a factorial analysis and a two-factor interaction analysis approach. The final discussion addresses the impact on the model's performance when modifications are made to significant variables identified by sensitivity analysis.

\subsection{Evaluating Noah-GEM $V_{d}$ Estimates}

The model results shown in Figs. 2, 3, 4, and 5 were obtained from a simulation with the default values of parameters in Noah-GEM-HRLDAS representative of a forest site. Figure 2 shows the observed and simulated ozone $V_{d}$ values for 7-12 June 2002 (wet) and 23-30 June 2002 (dry) periods. The model slightly underestimated $V_{d}$ for wet to moderate surface conditions for 7-12 June 2002, though it captured the day-to-day variability well. The model could not capture the high $V_{d}$ values $\left(14.2\right.$ and $11.7 \mathrm{~mm} \mathrm{~s}^{-1}$ ) in the afternoon after rain events 

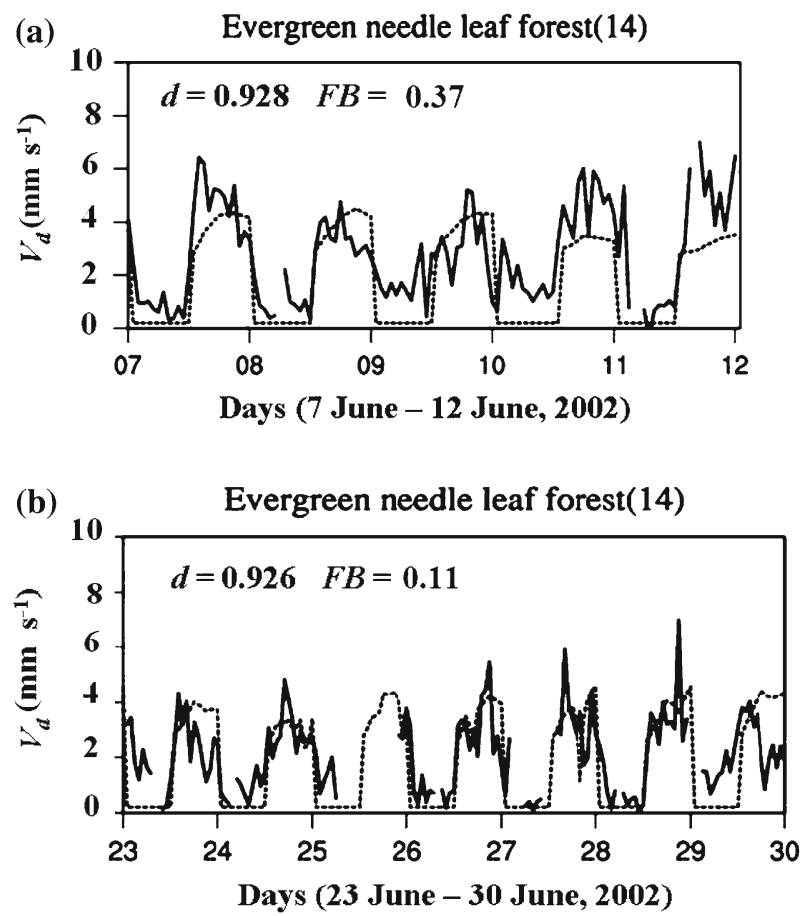

Fig. 2 Dry deposition velocity, $V_{d}$, time series for $L A I=4$. Solidline represents observations and dashedline is the model estimates. a The period 7-12 June 2002 was relatively wet. b The period 23-30 June 2002 corresponds to a relatively dry period. The variable, $d$, is the index of agreement and $F B$ is the fractional bias $\left(\mathrm{mm} \mathrm{s}^{-1}\right)$

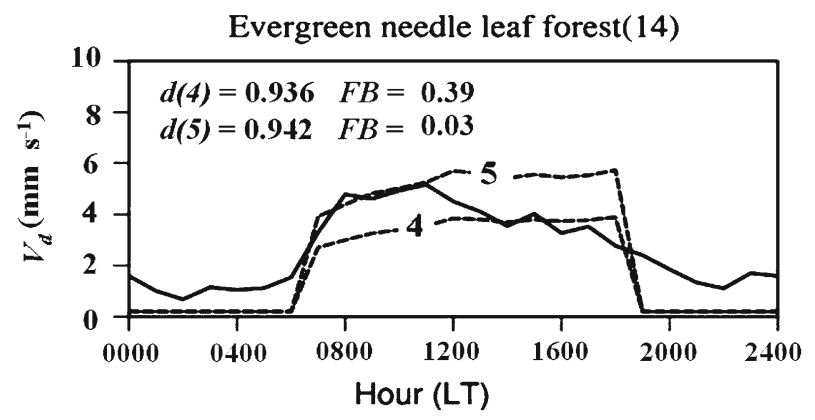

Fig. 3 Average diurnal dry deposition velocity $V_{d}$ for June 2002 over the Niwot Ridge study site. Solidline indicates observations. Dashedlines correspond to model results. The index of agreement is $d$; FB is the fractional bias $\left(\mathrm{mms}^{-1}\right)$ with the LAI of 4 and 5

on June 6, 2002 (not shown). Turnipseed et al. (2009) also noted this increase in $V_{d}$ after rain both as a possible impact of moist leaves leading to additional chemical interactions and as possible meteorological and non-stomatal feedbacks. The chemical interactions are currently not represented in the model. Under anomalously dry soil moisture conditions, the model is able to realistically capture the midday peak values and the diurnal variations in $V_{d}$. This is 
Fig. 4 The average diurnal aerodynamic resistance $\left(R_{a}\right)$, boundary-layer resistance $\left(R_{b}\right)$, and canopy resistance $\left(R_{C}\right)$ for June 2002 over the Niwot Ridge study site. Open circles with dashedline are observations. Solidlines correspond to model results. Model $R_{C}$ values for 0000-6000 and 1800-2400 LT have been set to maximum stomatal resistance $\left(R_{\mathrm{smax}}\right)$ measured as $5,000 \mathrm{~s} \mathrm{~m}^{-1}$

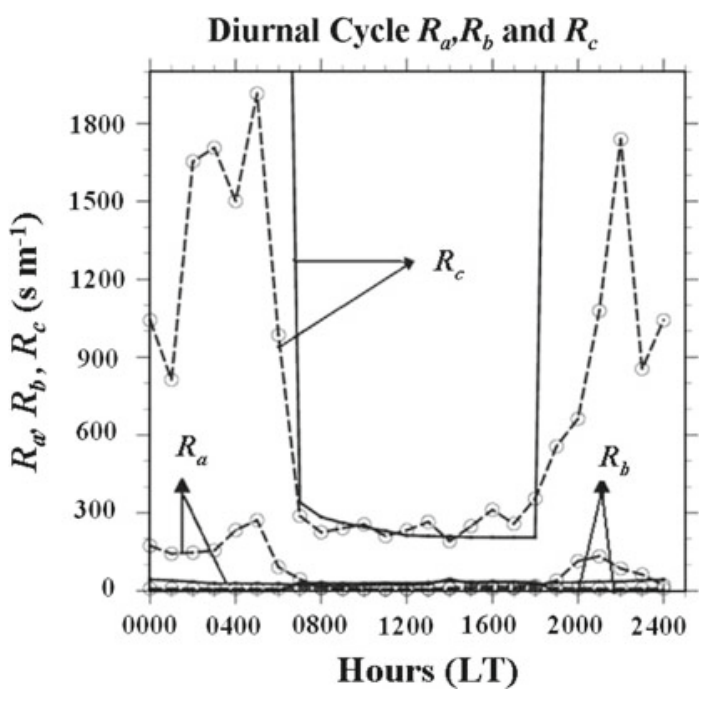

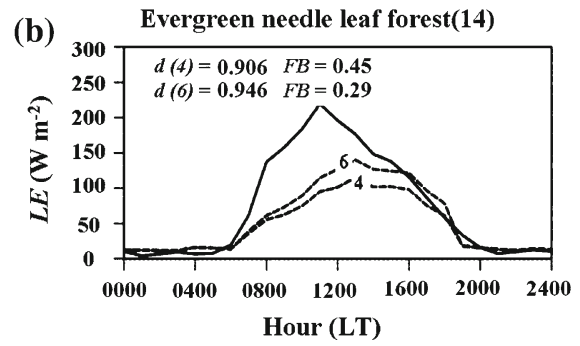

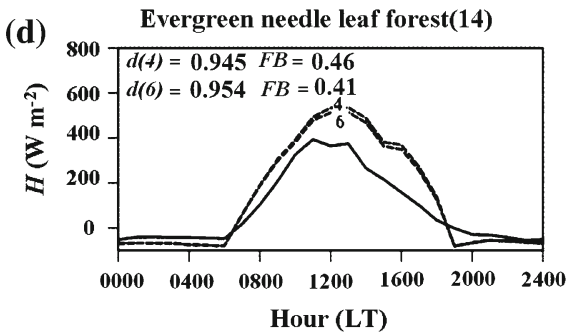

(d)

Hour (LT) (a)

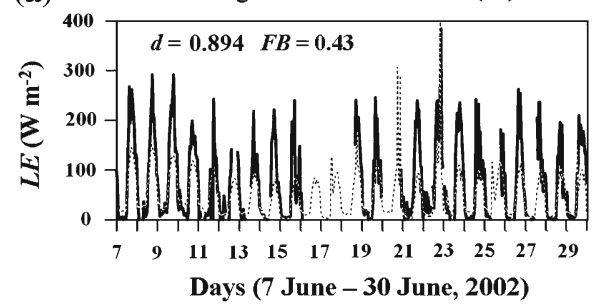

(c)

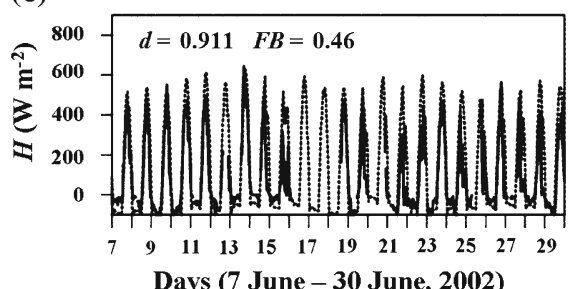

Evergreen needle leaf forest $(14)$

Days (7 June - 30 June, 2002)

Fig. 5 a Latent heat flux $(L E)$ and $\mathbf{c}$ sensible heat flux $(H)$ plots for 7-30 June $2002 \mathbf{b}$ and $\mathbf{d}$ average diurnal $L E$ and $H$ for 7-30 June 2002 over the Niwot Ridge study site. Solidline represents observations; dashedline represents model values. The period from 7-12 June 2002 was relatively wet while 23-30 June 2002 period corresponds to a relatively dry period. The term $d$ is the index of agreement while $F B$ is the fractional bias $\left(\mathrm{W} \mathrm{m}^{-2}\right)$ with $L A I=4$ and 6

reflected in the model index of agreement $(d)$ and bias $(F B)$ statistics for the wet and dry periods as $0.93 \pm 0.37$ and $0.93 \pm 0.11 \mathrm{~mm} \mathrm{~s}^{-1}$, respectively (Fig. 2).

Figure 3 shows the average diurnal $V_{d}$ variation for model simulations using different LAI values. When using $L A I=4$ (the default in Noah), the model underestimated the morning and nighttime $V_{d}$ values, but changing LAI values to 5 agreed better with daytime and early afternoon observations. For nighttime conditions, the model's $V_{d}$ values quickly fell to near zero while the observations showed values around $1.5-2 \mathrm{~mm} \mathrm{~s}^{-1}$. While the modelled $V_{d}$ 
values were calculated as the sum of $R_{a}, R_{b}$ and $R_{c}$, the mean diurnal variation of these resistances was also analysed (Fig. 4). Consistent with prior observations, $R_{c}$ was the dominant term giving values one to two orders of magnitude higher than $R_{a}$ and $R_{b}$. The model produced slightly lower than observed $R_{a}, R_{b}$, and $R_{c}$ values during daytime. The Noah LSM estimated $R_{C}$ value was notably different from the nighttime observations. In particular, the late evening dip in the model $V_{d}$ values appeared to be related to an increased $R_{c}$ in the Noah estimates. $R_{c}$ increased in response to cooling after sunset, and the observed $R_{c}$ was smaller than the constant value $\left(5,000 \mathrm{~s} \mathrm{~m}^{-1}\right)$ assumed in the model, and may be due to sporadic night transpiration in response to vapour pressure deficit and air temperature changes (Musselman and Minnick 2000; Cavender-Bare et al. 2007; Kavanagh et al. 2007; Fisher et al. 2007).

Since $R_{c}$ also affects the surface energy balance (Niyogi and Raman 1997), the modelled and observed latent $(L E)$ and sensible heat fluxes $(H)$ were also evaluated. The model underpredicted $L E$ while $H$ was in good agreement (Fig. 5). The model accurately identified most of the peaks in $L E$ but missed the late afternoon values particularly for the dry period (Fig. 5a, b). Similar results were seen for the sensible heat flux (Fig. 5c, d). The diurnal peaks of $L E$ were also shifted as compared to the observations. However, there are high uncertainties in both measuring and modelling latent heat fluxes. Because of the response of canopy resistance and the latent heat flux feedback, it appears that the model results were greatly affected by radiation. This may explain the underestimation of the high latent heat flux in the morning and afternoon hours. Furthermore, a dew related feedback, which is not accounted for in the model, may also be in action along with additional uncertainties in the model parameters. Further LAI calibrations could not overcome these mismatches.

To further diagnose the impact of surface parameters on the model performance, an ensemble sensitivity assessment was undertaken, which is discussed in the following sections.

\subsection{Sensitivity of $V_{d}$ to Soil and Vegetation Parameters}

The Noah-GEM model parameters were systematically altered as documented in Table 1. First, the vegetation parameters were changed one at time, involving changing the vegetation type while maintaining other parameters in their default setting. Then, for the rest of the experiments, the vegetation type was fixed to type 14 (evergreen needle leaf forest for the study site) and the other variables were modified. For example, LAI was changed from 1 through to 6, after which LAI was set to the default value and the green vegetation fraction was changed from 0.5 through to 0.9 in increments of 0.1 . The green vegetation fraction was then set back to default and the maximum stomatal resistance $\left(R_{\text {smax }}\right)$ value was modified from 1,000 to $7,500 \mathrm{~s} \mathrm{~m}^{-1}$, as shown in Table 1 . The corresponding changes in the model simulated $V_{d}$ were analysed. After assessing the sensitivity of the vegetation parameters, these parameters were reset to default values and the soil texture parameters were then changed to test the model's sensitivity. For example, the vegetation type was changed from 14 (default) to 13 , then before changing the soil parameter, the vegetation type must be changed back to the default value (14). For these cases, the model was run for every soil texture while other values were retained at default. Following this, the sensitivity of individual soil properties was considered while the soil texture was set to default. The values and the experiments are listed in Table 1.

Figure 6a shows the $V_{d}$ variation for the four different vegetation types. The $V_{d}$ values increased when the vegetation type was changed from evergreen needle leaf forest to deciduous needle leaf forest and mixed forest. Evergreen needle leaf forest also had the lowest $V_{d}$ variations. The $V_{d}$ values over mixed and deciduous needle leaf forest ranged from 

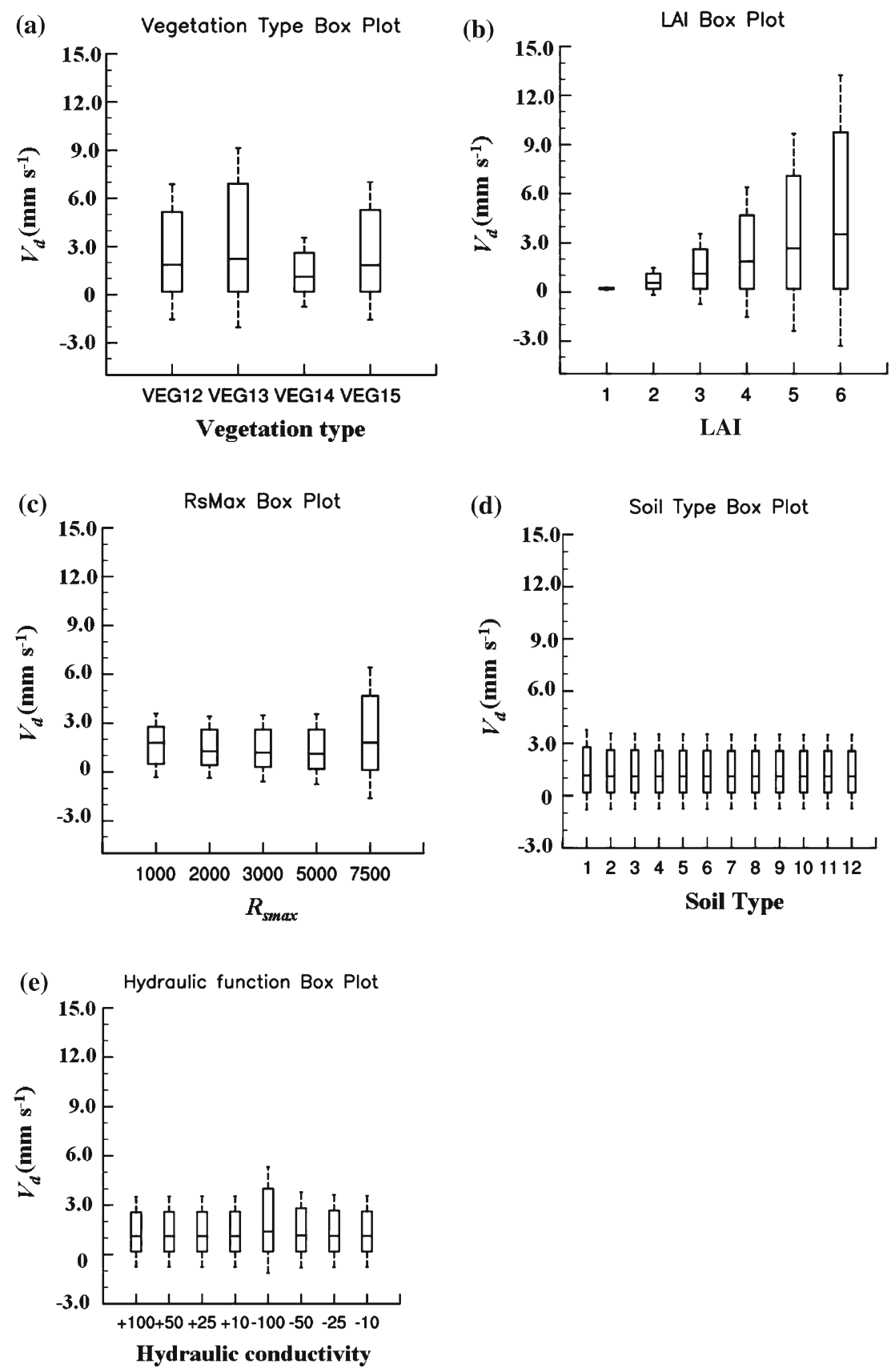

Fig. 6 Box plots for June 2002 dry deposition velocity $\left(V_{d}\right)$ with different parameter changes: a vegetation type, $\mathbf{b}$ leaf area index, $\mathbf{c}$ maximum stomatal resistance $\left(R_{\mathrm{Smax}}, \mathrm{sm}^{-1}\right)$, d soil texture, and e hydraulic function over the Niwot Ridge study site. The solidline is observations. Dashedline corresponds to model results. Soil types were classified as (1) sand, (2) loamy sand, (3) sandy loam, (4) silt loam, (5) silt, (6) loam, (7) sandy clay loam, (8) silty clay loam, (9) clay loam, (10) sandy clay, (11) silty clay, and (12) clay. VEG 12 refers to the deciduous needle leaf forest; VEG13 refers to the evergreen broadleaf forest; VEG14 refers to the evergreen needle leaf forest; VEG15 refers to the mixed forest 
$0.0-4.0 \mathrm{~mm} \mathrm{~s}^{-1}$ respectively. The $V_{d}$ values were highly sensitive to leaf area index prescription (Fig. 6b). Lower LAI values resulted in smaller $V_{d}$ values, which were expected since the $R_{c}$ in the model was estimated by scaling it with LAI values of each vegetation type. Therefore, higher LAI leads to lower total $R_{c}$ values (not shown) and higher $V_{d}$ values.

Figure 6c shows the sensitivity of $V_{d}$ to $R_{\text {smax }}$, which is currently an arbitrary constant in the Noah model based on Noilhan and Planton (1989). The $R_{\text {smax }}$ value directly affects the nighttime $R_{c}$ and hence $V_{d}$ values. Interestingly, the $R_{\text {smax }}$ specification also affects the daytime $R_{c}$ due to impacts on the maximum photosynthesis rate calculation in the GEM model and the F1 term (a function of the amount of photosynthetically-active radiation in the Jarvis type $R_{c}$ scheme in the default Noah). The $V_{d}$ (and $R_{c}$ ) values ranged from $1-4 \mathrm{~mm} \mathrm{~s}^{-1}$ to $2-7 \mathrm{~mm} \mathrm{~s}^{-1}$ (from 2,000-7,500 $\mathrm{s} \mathrm{m}^{-1}$ ) as seen in Fig. 6c, consistent with previous studies using other $V_{d}$ models. For example, Walmsley and Wesely (1996); Finkelstein et al. (2000) and Pleim et al. (2001) found a similar sensitivity to LAI and $R_{\text {smax }}$ in the Wesely deposition scheme.

Uncertainties in the soil texture had little impact on $V_{d}$ values (Fig. 6d), and even with the extreme change in soil texture from clay to sand, there was little impact on the model results. Examining the average diurnal plots (not shown) reveals that the effect was noticeable only during the late afternoon. Modelled $V_{d}$ values were somewhat sensitive to both the hydraulic function (Fig. 6e) and maximum soil moisture content (particularly when it was reduced, results not shown). However, many other parameters caused no significant changes in $V_{d}$ values (figures not shown): albedo, emissivity, surface roughness, green vegetation fraction, dry soil moisture content, reference soil moisture content, saturated soil hydraulic conductivity, saturated soil water diffusivity, soil moisture wilting point at which transpiration ceases, and quartz content.

A number of studies, e.g. Noilhan and Planton (1989); Pleim AND Xiu (1995); Chen et al. (1996); Betts et al. (1997); Niyogi et al. (1999), identified LAI and vegetation fraction as first-order parameters that affect the land-surface model performance, particularly when reviewing surface energy fluxes. Our study also identified that both LAI and vegetation fraction have a dominant impact on latent heat flux (figure not shown), but only LAI had a significant impact on $V_{d}$ values. Similarly, when considering the effect of soil texture, sand and loamy sand caused the lowest latent heat fluxes. This was due to the corresponding changes in soil parameters such as hydraulic function and saturated soil hydraulic conductivity. There was, however, a limited impact on $V_{d}$ values as discussed earlier.

The impact of soil moisture on $V_{d}$ was examined next (figure not shown). Soil moisture is a prognostic variable and the model system was run for several months to eliminate the memory of the initial conditions. Therefore, it is impossible to see the effect of initial soil moisture on the model results. Instead, we reviewed the relationships between coincident soil moisture and $V_{d}$, (Fig. 7) and latent heat flux and $V_{d}$ at 1400 LT each day for June 2002 (Figure not shown). Latent heat flux and $V_{d}$ values only showed a better correlation under low LAI conditions (cf. Pleim et al. 1999). The $V_{d}$ value and soil moisture also correlated well at the lower LAI values. As expected, $V_{d}$ and $R_{c}$ correlated well regardless of changes in vegetation types, $L A I$, or $R_{\text {smax }}$ (Fig. 8). Reviewing these results, we concluded that the major parameters affecting $V_{d}$ (and $R_{c}$ ) are vegetation type, $L A I$, soil texture, and $R_{s m a x}$.

\subsection{Factorial Analysis}

Building on the results of the one-at-time sensitivity testing, the impacts of multiple variable changes and interactions were analysed next. For this we used a factorial based Pareto analysis (Haaland 1989; Niyogi et al. 1999). Pareto plots are graphical representations of 

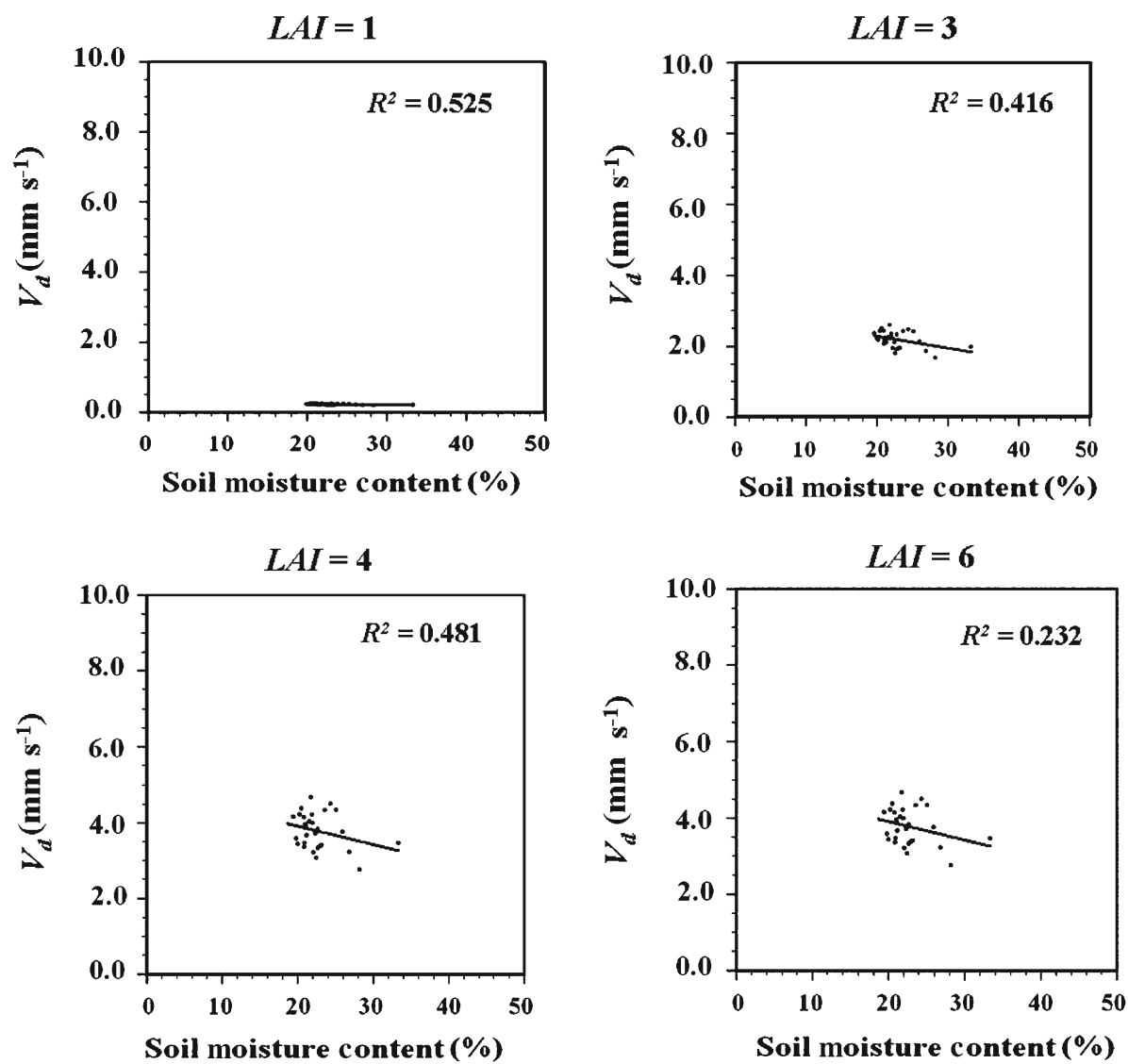

Fig. 7 Scatter plots of dry deposition velocity $\left(V_{d}\right)$ and soil moisture content for different LAI values from 1 to 6 , for June 2002 at 1400 LT

the direct (main) effects and the interaction terms between the model variables or between input parameters (e.g. Fig. 9). Pareto plots consist of bar graphs that display a percentage of the sum of mean squares of the effect ( $V_{d}$ in this case), and a line graph that presents the cumulative percentage for each category. Figure 9 shows a pareto plot for the model runs corresponding to four variables: $L A I$, vegetation type, $\mathrm{R}_{\text {smax }}$, and soil texture (from Table 1 ).

In the plot, the bars for leaf area index and vegetation type (Veg) present the individual effects while the bars corresponding to Veg:LAI represent the interaction effect between vegetation type and leaf area index. The size of the bar is an indication of the sensitivity of the effect. For example in Fig. 9a, b, LAI is the dominant term affecting the simulation for both wet (7-12 June 2002) and dry conditions (23-30 June 2002). Additionally the model $V_{d}$ results show a secondary dependence on vegetation types (Veg) and vegetation type interaction with leaf area index (Veg:LAI). Interactions of maximum stomata resistance $\left(R_{\text {smax }}\right)$ and maximum stomata resistance with leaf area index $\left(R_{\text {smax }}: L A I\right)$ were the next most important factors affecting $V_{d}$ sensitivity. After removing $L A I$ as an independent factor, $R_{\text {smax }}$ became the dominant variable affecting $V_{d}$ variations. The pareto analysis, thus, highlights the significance of $L A I$ and $R_{s \max }$ as the two most important terms affecting the model's $V_{d}$ values. 

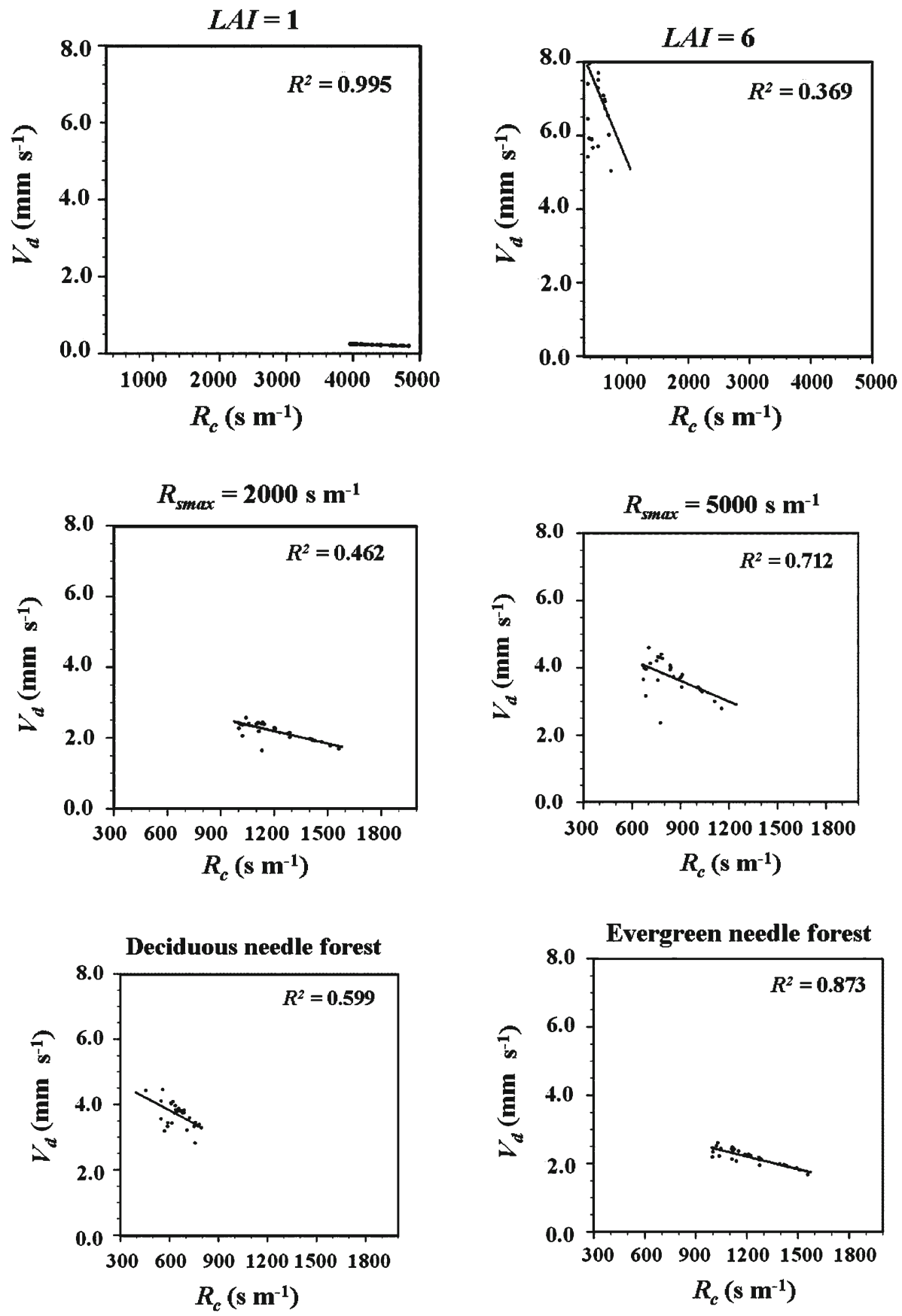

Fig. 8 Scatter plots of dry deposition velocity $\left(V_{d}\right)$ and canopy resistance $\left(R_{c}\right)$ for different LAI, maximum stomata resistance $\left(R_{\text {Smax }}\right)$ and vegetation types for June 2002 at 1400 LT 


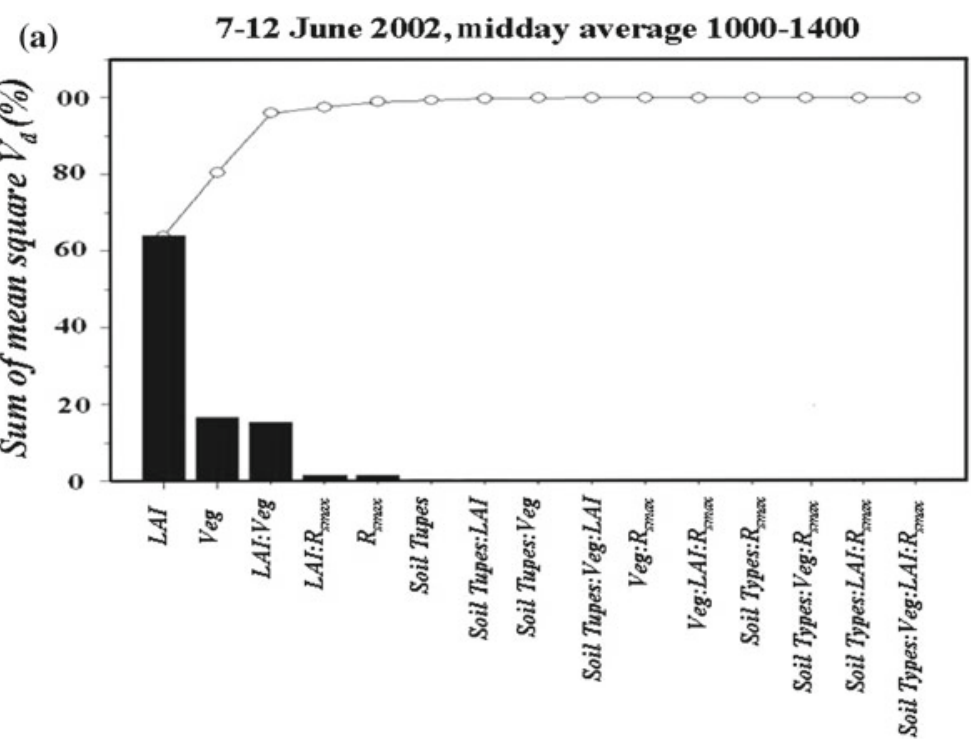

(b) 23-30 June 2002, midday average 1000-1400

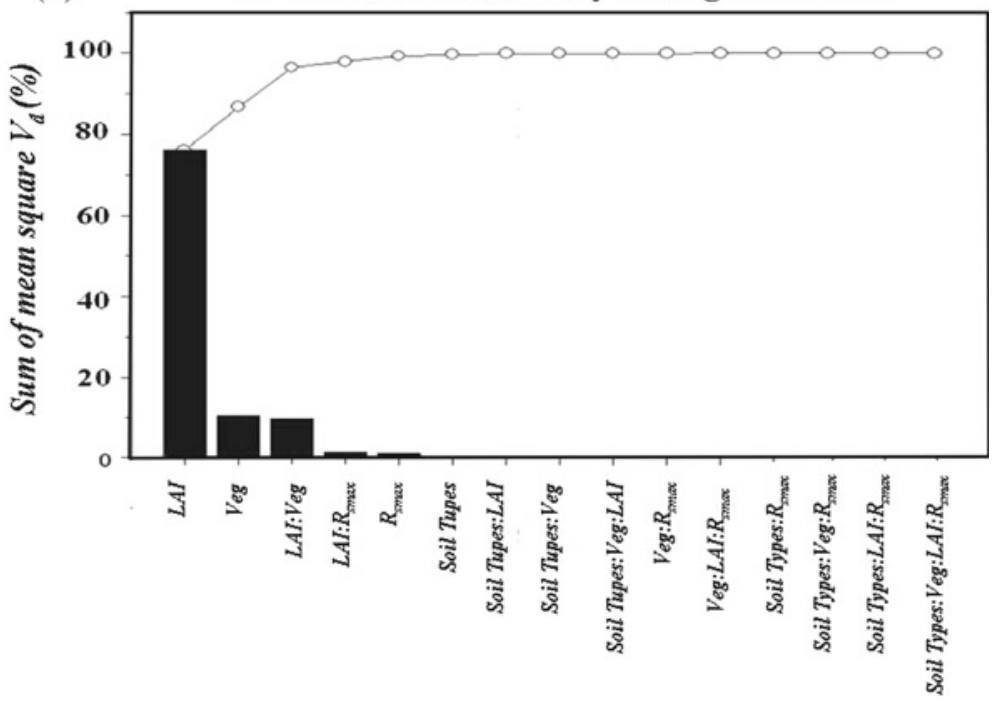

Fig. 9 Pareto plots of the sum of the square of the dry deposition velocity, $V_{d}(\%)$, for different values of leaf area index, vegetation type $(\mathrm{Veg})$, maximum stomatal resistance $\left(R_{\mathrm{Smax}}\right)$, and soil textures for a 7-12 June 2002 (relatively wet) and b 23-30 June 2002 (relatively dry) periods

\subsection{Two-Factor Interaction Analysis}

The two-factor interaction analysis (TFI) illustrates more explicitly the interactions identified in the Pareto analysis. TFI uses two-way analysis of variance (ANOVA) to calculate the significance of the two factors and their interaction. In the TFI plot, the slopes of the lines 

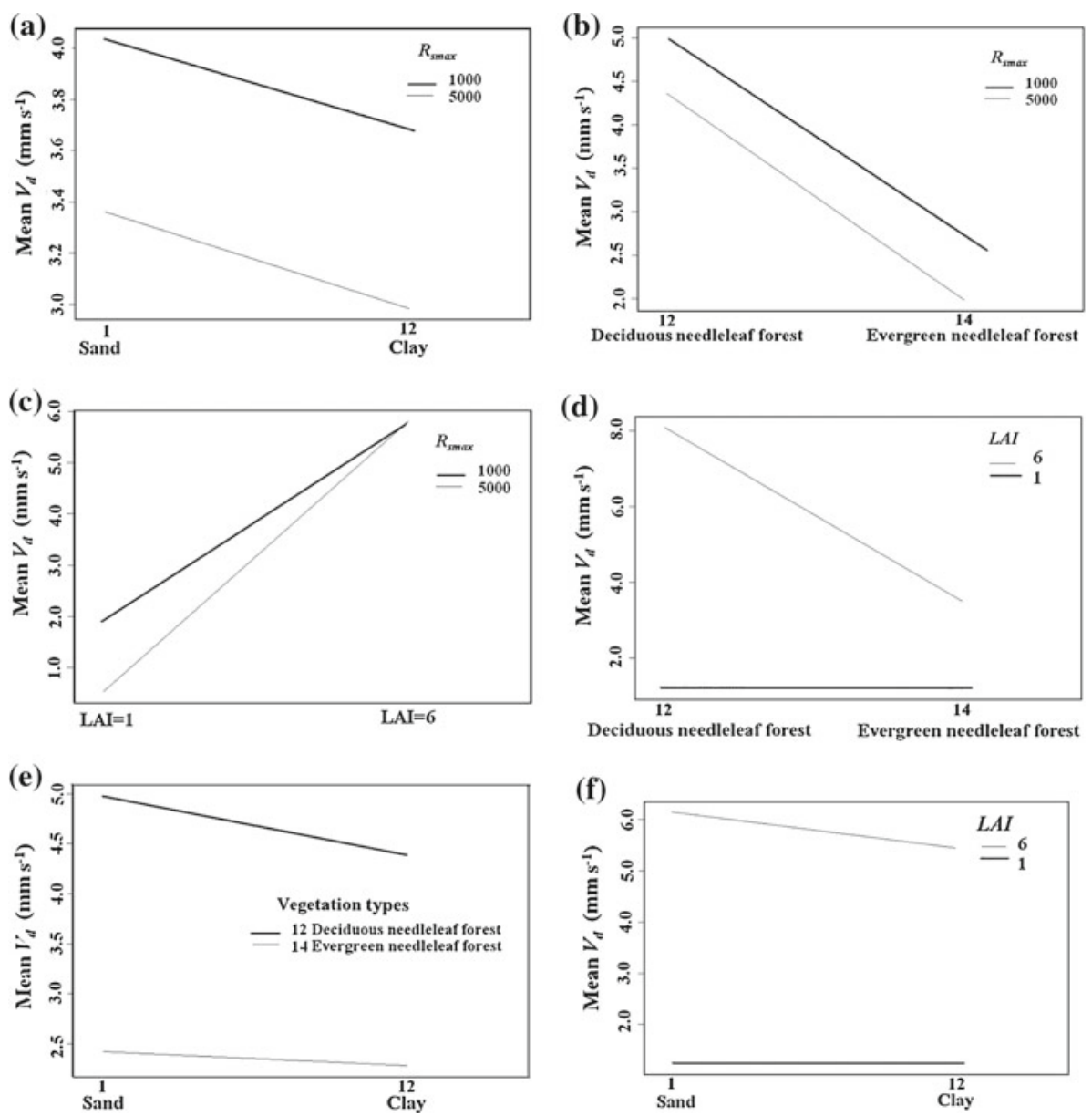

Fig. 10 Interaction plots of dry deposition velocity $\left(V_{d}\right)$ with a maximum stomatal resistance $\left(R_{\mathrm{Smax}}\right)$ and soil texture, b with $R_{\mathrm{Smax}}$ and vegetation type, $\mathbf{c}$ with $R_{\mathrm{Smax}}$ and leaf area index, $\mathbf{d}$ with $L A I$ and vegetation type, e with vegetation type and soil texture, and $\mathbf{f}$ with $L A I$ and soil texture for 7-12 June 2002

for different variable settings provide information regarding the sensitivity of a variable in the model (Niyogi et al. 1999). Thus, the interpretation of the results depends on the slope of the interaction plots. Figure 10 shows the TFI plots for $R_{\text {smax }}$, vegetation type, and soil texture (cf. Fig. 9). In Fig. 10a, b, the $R_{\text {smax }}$ and vegetation type interaction, as well as the $R_{\text {smax }}$ and soil texture interaction, results in parallel lines. This suggests a limited interaction between the two parameters when estimating $V_{d}$ values. On the other hand, Fig. 10c shows that the two lines of $R_{\text {smax }}$ and $L A I$ are not parallel and indicate a high degree of interaction. In particular, as the two lines show a larger difference at lower LAI values, this indicates a high sensitivity of $R_{\text {smax }}$ at lower LAI. Similarly, when reviewing the slopes for $R_{\text {smax }}$ lines, the slope for higher $R_{\text {smax }}$ suggests that the sensitivity of $L A I$ to $V_{d}$ estimation is higher for higher $R_{\text {smax }}$ slopes. The interaction terms also show higher sensitivity of vegetation type for higher LAI. Similarly, Fig. 10d shows that the sensitivity and uncertainty of $V_{d}$ are more pronounced for deciduous needle leaf when compared to evergreen needle leaf forest, 


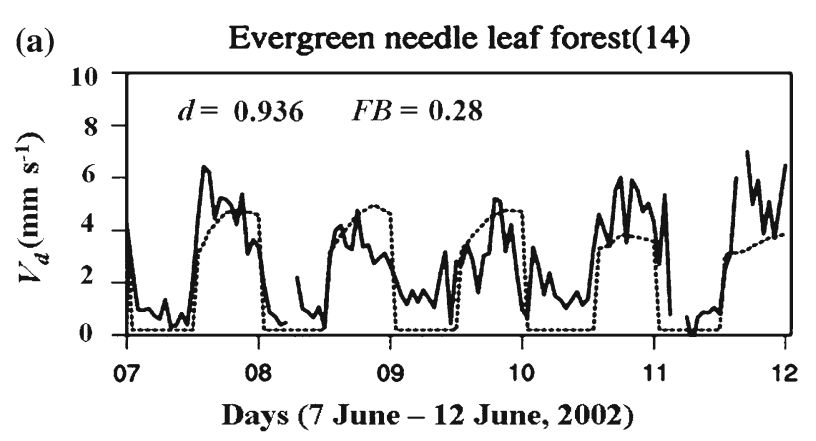

(b) Evergreen needle leaf forest(14)

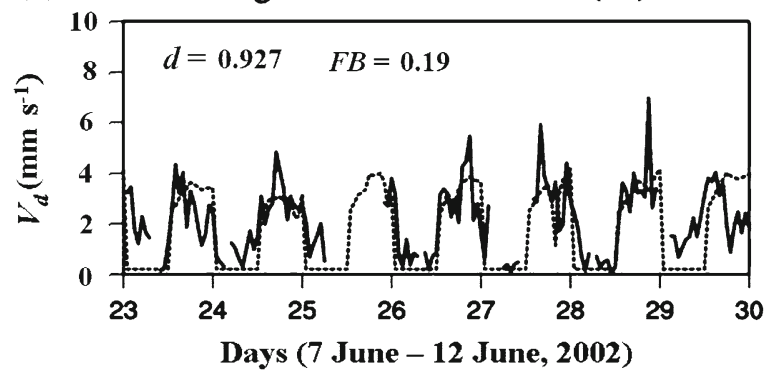

Fig. 11 Dry deposition velocity $\left(V_{d}\right)$ time series plots for a 7-12 June 2002 with the $L A I=4.2$ and b 23-30 June 2002 with the $L A I=3.8$. Observed $V_{d}$ (solidline) and modelled $V_{d}$ (dashedline) over evergreen needle leaf forest (14) during wet period, 7-12 June 2002 and dry period, 23-30 June 2002. The variable, $d$, is the index of agreement and $F B$ is the fractional bias $\left(\mathrm{mm} \mathrm{s}^{-1}\right)$

as the LAI increases (Fig. 10d). Figure 10e and $\mathrm{f}$ shows minor interaction effects between vegetation type and $L A I$ as a function of soil texture. The interactions between $L A I, R_{\text {smax }}$, vegetation types, and soil textures impacting $V_{d}$ were relatively insensitive to soil moisture (figure not shown). Again, when compared to surface energy fluxes, the $V_{d}$ results appear to be, generally, only sensitive to $L A I, R_{\text {smax }}$, and vegetation type specification.

\subsection{Model Modifications}

The sensitivity analysis indicates that $L A I$ and $R_{\text {smax }}$ appear to be the critical variables affecting $V_{d}$ estimates. Therefore, the default LAI value was modified to reflect the canopy phenological changes over the study site that have been observed when $L A I=4.2$. The resulting model performance showed better agreement for the wet period when $L A I=4.2$ and for the dry period when $L A I=3.8$ (Fig. 11). This outcome highlights a need for assimilating variable $L A I /$ normalized difference vegetation index (NDVI) or having dynamic LAI within the model for future work. During the dry period, the decreased $V_{d}$ may not be directly caused by reduced LAI. Rather, it might have been due to soil moisture conditions, which control maximum catalytic rubisco capacity $\left(V_{\max }\right)$ for calculating $R_{c}$. Consequently, another variable, $R_{\text {smax }}$, was tested by reducing the current default value. Tests with a range of observed values suggested that a value of $1,250 \mathrm{~s} \mathrm{~m}^{-1}$ during the wet period and $1,700 \mathrm{~s} \mathrm{~m}^{-1}$ during the dry period produced the best results, corresponding to increased $V_{d}$ values during nighttime (Fig. 12). Future efforts should be directed towards additional improvements for nighttime 

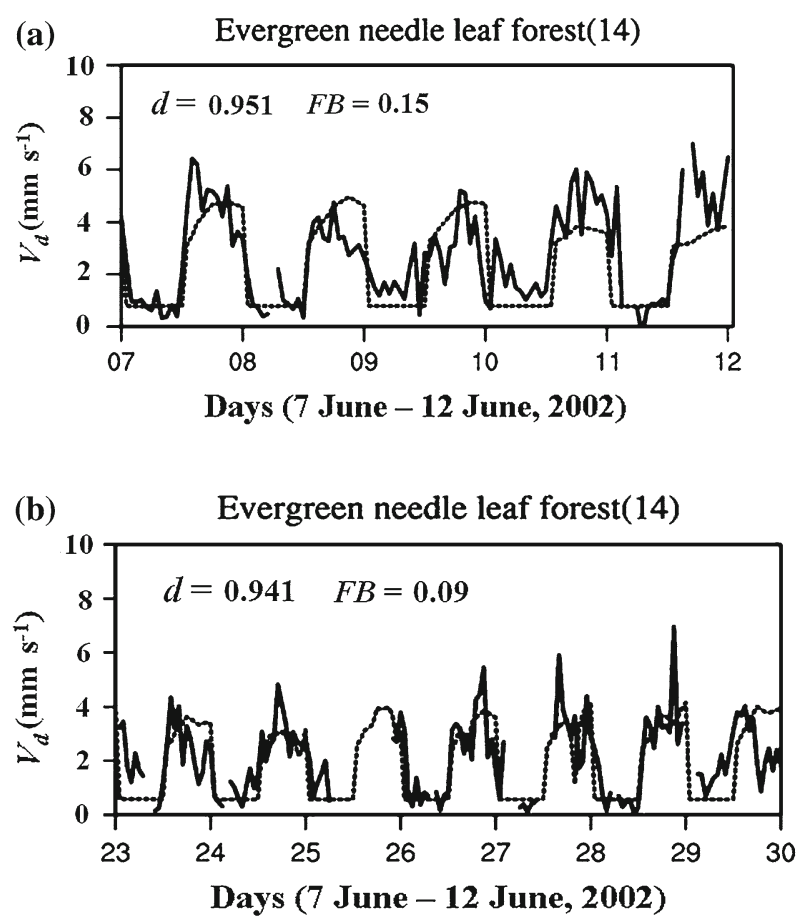

Fig. 12 Dry deposition velocity $\left(V_{d}\right)$ time series plots for a 7-12 June 2002 (relatively wet) period with the $L A I=4.2$ and the $R_{\mathrm{Smax}}$ of $1,250 \mathrm{~s} \mathrm{~m}^{-1} \mathbf{b}$ for 23-30 June 2002 (relatively dry) period, with the $L A I=3.8$ and the $R_{\text {smax }}$ of $1,700 \mathrm{~s} \mathrm{~m}^{-1}$. Observed $V_{d}$ (solidline) and modelled $V_{d}$ (dashedline). The variable, $d$, is the index of agreement and $F B$ is the fractional bias $\left(\mathrm{mm} \mathrm{s}^{-1}\right)$

$R_{c}$ by considering radiation, hydraulic conductivity, vapour pressure deficit, leaf age, and canopy turbulence (Snyder et al. 2003; Bucci et al. 2003; Daley and Phillips 2006; Kavanagh et al. 2007; Mairgareth et al. 2007; Turnipseed et al. 2009).

\subsection{Further Performance Test}

To further demonstrate the positive impact of the changes recommended in $L A I$ and $R_{\text {smax }}$, we applied the model over two different sites: Bondville, Illinois (agriculture site) and Duke Forest (needle leaf site). At both these locations, only energy flux observations were available for verification. The model was run with four configurations: (i) default, (ii) change in leaf area index with a higher value for the wet period and lower value for the dry period, (iii) with lower $R_{\text {smax }}$ values, and (iv) by changing both the leaf area index and $R_{\text {smax }}$. The $L A I$, $R_{\text {smax }}$ changes were linked to the soil conditions (SMC in Eq. 4).

$$
\begin{aligned}
\text { Corrected } L A I & =\frac{L A I}{(0.95+(0.1 S M C))}, \\
S M C & =\frac{W_{2}-W_{\text {wilt }}}{W_{\max }-W_{\text {wilt }}},
\end{aligned}
$$

where $L A I$ is leaf area index, $W_{2}$ is the deep soil moisture content $\left(\mathrm{m}^{3} \mathrm{~m}^{-3}\right), W_{\text {wilt }}$ is the wilting point soil moisture $\left(\mathrm{m}^{3} \mathrm{~m}^{-3}\right)$, and $W_{\max }$ is the maximum soil moisture content $\left(\mathrm{m}^{3} \mathrm{~m}^{-3}\right)$. 
Table 2 Summary of the fractional bias $\left(\mathrm{W} \mathrm{m}^{-2}\right)$ of sensible heat flux $(H)$ and latent heat flux $(L E)$ over Duke Forest and Bondville study sites

\begin{tabular}{llllll}
\hline Runs & Duke forest & & & \multicolumn{2}{l}{ Bondville } \\
\cline { 2 - 3 } & $H$ bias $\left(\mathrm{W} \mathrm{m}^{-2}\right)$ & $L E$ bias $\left(\mathrm{W} \mathrm{m}^{-2}\right)$ & & $H$ bias $\left(\mathrm{W} \mathrm{m}^{-2}\right)$ & $L E$ bias $\left(\mathrm{W} \mathrm{m}^{-2}\right)$ \\
\hline Default & -0.304 & 0.206 & -0.314 & 0.123 \\
Obs-Both_correct & -0.287 & 0.182 & -0.294 & 0.105 \\
Obs-corrected LAI & -0.288 & 0.186 & -0.300 & 0.112 \\
Obs-corrected $R_{\text {Smax }}$ & -0.303 & 0.202 & & -0.308 & 0.116 \\
\hline
\end{tabular}

Obs is observed data. Both_correct indicates $L A I$ and $R_{\text {Smax }}$ have been corrected; corrected LAI:LAI has been corrected and corrected $\mathrm{R}_{\mathrm{Smax}}: R_{\mathrm{Smax}}$ has been corrected

The new parameter values were estimated using

$$
\begin{aligned}
L A I & =L A I / L A I_{\text {corr }}, \\
\text { Corrected }_{\text {smax }} & =\frac{R_{\text {smax }}}{L A I / L A I_{\text {corr }}},
\end{aligned}
$$

where $L A I_{\text {corr }}$ is the corrected LAI. Using these equations, the leaf area index was set from 4 to 4.12 for the Duke Forest site and from 4 to 4.19 for the Bondville site. The $R_{\text {smax }}$ ranged from 1,214 to $1,232 \mathrm{~s} \mathrm{~m}^{-1}$ for Duke Forest and from 1,194 to $1,218 \mathrm{~s} \mathrm{~m}^{-1}$ for Bondville. Results showed small differences but overall positive improvements in the model performance as summarized in Table 2.

\section{Conclusions}

The deposition velocity estimation capability of the Noah/HRLDAS model, based on a photosynthesis-based canopy resistance model (GEM), was evaluated with observations from a conifer forest at the Niwot Ridge AmeriFlux site, Colorado, USA. The observations and model results were analysed and compared for two different periods, 7-12 June 2002 (relatively wet soil) and 23-30 June 2002 (relatively dry soil). Using the default $L A I=4$, the model performed well for wet to moderately wet soil conditions but slightly overestimated $V_{d}$ for the dry period. In general, the model simulates the daytime variation of $V_{d}$ but has difficulty in treating the nighttime canopy and aerodynamic resistances. A large number (112) of model experiments were conducted for testing the sensitivity of the model to different soil and vegetation parameters, and showed that the $V_{d}$ estimation was mostly sensitive to the $L A I$ and $R_{\text {smax }}$ prescription. Vegetation type had a modest impact as did soil moisture and soil texture specifications. Soil and vegetation parameters such as soil texture and vegetation fraction had a larger impact on the latent heat flux estimation than on $V_{d}$ estimates. Our results suggest that the Noah land-surface model performance can be improved by changing both the specifications of LAI dynamics or phenology and the $R_{\text {smax }}$ prescription. Additional experiments were performed by changing $L A I$ and $R_{\text {smax }}$. Our results showed that the GEM-Noah-HRLDAS model's framework can be effectively applied to estimate deposition velocity values for air quality/biogeochemical studies, particularly when land-surface conditions are accurately prescribed.

We recommend that future improvements of the Noah LSM should focus on including the assimilation of NDVI data and incorporating a dynamic LAI estimation into the 
deposition and canopy resistance model. Additionally, it was noted that the $R_{\text {smax }}$ specification within the Noah model needs further evaluation based on recent studies that suggest nighttime transpiration of each species (Synder et al. 2003).

Acknowledgments This research benefited through the NOAA/JCSDA grant (NA06NES4400013), NCAR BEACHON (Bio-hydro-atmosphere interactions of Energy, Aerosols, Carbon, $\mathrm{H}_{2} \mathrm{O}$, and Organics \& Nitrogen) Program, NASA Terrestrial Hydrology Program (Dr. Jared Entin), and NSF CAREER (Drs. Liming Zhou and Jay Fein). It was also supported by the National Natural Science Foundation of China (NSFC Grant No. 40875076). The observation data from NWR AmeriFlux sites has been provided by Dr. Russ Monson (http:// public.ornl.gov/ameriflux/Site_Info/siteInfo.cfm?KEYID=us.niwot_ridge.01).

\section{Appendix A: Deposition Velocity Algorithm}

A simplified dry deposition velocity $\left(V_{d}\right)$ module is considered in the HRLDAS. $V_{d}$ is estimated from the aerodynamic resistance $\left(R_{a}\right)$, the laminar boundary-layer resistance $\left(R_{b}\right)$ and the canopy resistance $\left(R_{c}\right)$ (Wesely 1989$)$ as,

$$
V_{d}=\left(R_{a}+R_{b}+R_{c}\right)^{-1},
$$

while the aerodynamic resistance $\left(R_{a}\right)$ is calculated as a function of wind speed $\left(\mathrm{m} \mathrm{s}^{-1}\right)$ (Lui et al. 2007).

$$
R_{a}=94.909 u^{-0.9036}
$$

The boundary-layer resistance $\left(R_{b}\right)$ is derived following Nikolov et al. (1995), as used by Niyogi et al. (2003) for free convection $\left(R_{b f c}\right)$ and forced convection $\left(R_{b f r}\right)$ conditions,

$$
\begin{gathered}
\frac{1}{R_{b f c}}=c T^{0.56}\left[(T+120) \frac{u}{P d}\right]^{0.5}, \\
\frac{1}{R_{b f r}}=c T_{s}^{0.56}\left\{\frac{T_{s}+120}{P}\right\}^{0.5}\left\{\frac{T_{v s}-T_{v a}}{d}\right\}^{0.25} .
\end{gathered}
$$

In the above, $T$ is the air temperature (in kelvin, $\mathrm{K}$ ), $T_{s}$ is the surface temperature, while $T_{v s}$ and $T_{v a}$ are virtual surface and virtual air temperatures $(\mathrm{K}) ; u$ is the wind speed $\left(\mathrm{m} \mathrm{s}^{-1}\right), P$ is the pressure $(\mathrm{Pa})$, and $d$ is the leaf length scale $(\mathrm{m}) ; c$ is a scaling constant that equals $4.322 \times 10^{-3}$ for broad leaves and $1.203 \times 10^{-3}$ for conifers (Nikolov et al. 1995).

The canopy resistance $\left(R_{c}\right)$ is considered the primary resistance term to estimate $V_{d}$ and is assumed to include both the stomatal and non-stomatal processes. The $R_{c}$ term in the Noah-GEM model is calculated from the Ball-Berry approach (Ball et al. 1987) as

$$
1 / R_{c}=m \frac{A_{n}}{C_{s}} h_{s}+b
$$

where $A_{n}\left(\mathrm{~mol} \mathrm{~m}^{-2} \mathrm{~s}^{-1}\right)$ is the photosynthesis rate, $h_{s}(\%)$ is the relative humidity at the canopy surface, and $C_{s}\left(\mathrm{~mol} \mathrm{~m}^{-3}\right)$ is the $\mathrm{CO}_{2}$ concentration at the canopy surface. The terms $m$ and $b$ are the species-specific gas exchange constants. Details regarding the formulations and constants can be found in Niyogi et al. (2003, 2006, 2009). The photosynthesis rate $\left(A_{n}\right)$ depends on three main factors: the rubisco limitation $\left(W_{c}\right)$, the amount of photosynthetically-active radiation $\left(W_{e}\right)$, and the capacity of the $\mathrm{C} 3$ vegetation to utilize the photosynthesis products or the phophoenolpyruvate carboxylase limitation in C4 vegetation $\left(W_{s}\right)$. The terms $W_{c}$ and $W_{s}$ are a function of the maximum catalytic rubisco capacity for the 
leaf $\left(V_{m}\right)$ derived from temperature and soil moisture. The $W_{e}$ term is a function of radiation, $\mathrm{CO}_{2}$ concentration, and the $\mathrm{CO}_{2}$ compensation point.

\section{References}

Alfieri JG, Niyogi D, Blanken PD, Chen F, LeMone MA, Mitchell KE, Ek MB, Kumar A (2008) Estimation of the minimum canopy resistance for croplands and grasslands using data from the 2002 International H2O Project. Mon Weather Rev 136:4452-4469

Baldocchi DD, Hicks BB, Camara P (1987) A canopy stomatal resistance model for gaseous deposition to vegetated surfaces. Atmos Environ 21:91-101

Ball J, Woodrow I, Berry J (1987) A model predicting stomatal conductance and its contribution to the control of photosynthesis under different environmental conditions. Prog Photosynth Res 4:221-224

Betts R, Cox P, Lee S, Woodward F (1997) Constrating physiological and structural vegetation feedbacks in climate change simulations. Nature 387:796-799

Bucci SJ, Scholz FG, Goldstein G, Meinzer FC, Sternberg LSL (2003) Dynamic changes in hydraulic conductivity in petioles of two savanna tree species: factors and mechanisms contributing to the refilling of embolized vessels. Plant Cell Environ 26:1633-1645

Cavender-Bare J, Sack L, Savage J (2007) Atmospheric and soil drought reduce nocturnal conductance in live oaks. Tree Physiol 27:611-620

Chen F, Dudhia J (2001) Coupling an advanced land surface-hydrology model with the Penn State-NCAR MM5 modelling system. Part I: model implementation and sensitivity. Mon Weather Rev 129:569-585

Chen F, Mitchell K, Schaake J, Xue Y, Pan H, Koren V, Duan Y, Ek M, Betts A (1996) Modelling of landsurface evaporation by four schemes and comparison with FIFE observations. J Geophys Res 101:72517268

Chen F, Manning KW, LeMone MA, Trier SB, Alfieri JG, Roberts R, Tewari M, Niyogi D, Horst TW, Oncley SP, Basara JB, Blanken PD (2007) Description and evaluation of the characteristics of the NCAR high-resolution land data assimilation system. J Appl Meteorol Climatol 46:694-713

Cooter EJ, Schwede D (2000) Sensitivity of the national oceanic and atmospheric administration multiplayer model to instrument error and parameterization uncertainty. J Geophys Res 105:6695-6704

Daley MJ, Phillips NG (2006) Interspecific variation in nighttime transpiration and stomatal conductance in a mixed New England deciduous forest. Tree Physiol 26:411-419

Ek MB, Mitchell KE, Lin Y, Rogers E, Grunmann P, Koren V, Gayno G, Tarpley JD (2003) Implementation of Noah land surface model advances in the national centers for environmental prediction operational mesoscale eta model. J Geophys Res 108:8851

Erisman JW, van Pul A, Wyers P (1994) Parameterization of surface resistance for the quantification of atmospheric deposition of acidifying pollutants and ozone. Atmos Environ 28:2595-2607

Finkelstein PL, Ellestad TG, Clarke JF, Meyers TP, Schwede DB, Hebert EO, Neal JA (2000) Ozone and sulfur dioxide dry deposition to forests: observations and model evaluation. J Geophys Res 105:365-377

Fisher JB, Baldocchi DD, Mission L, Dawson TE, Goldstein AH (2007) What the towers don't see at night: nocturnal sap flow in trees and shrubs at two AmeriFlux sites in California. Tree Physiol 27:597-610

Fulton RA, Breidenbach JP, Seo DJ, Miller DA, Bannon TO (1998) The WSR-88D rainfall algorithm. Weather Forecast 13:377-395

Garland JA, Atkins DHF, Readings CJ, Caughey SJ (1974) Deposition of sulphur dioxide to the ground. Atmos Environ 8:75-79

Grell AG, Peckham SE, Schmitz R, McKeen SA, Frost G, Skamarock WC, Eder B (2005) Fully coupled "Online" Chemistry within the WRF model. Atmos Environ 39:6957-6975

Haaland PD (1989) Experimental design in biotechnology. Marcel Dekker Inc., New York, 105 pp

Hicks BB, Baldocchi DD, Hosher RP, Hutchison BA, Matt Dr, McMillen RT, Satterfield LC (1985) On the use of monitor air concentrations to infer dry deposition. NOAA technical memorandum ERLO ARLZ141, $65 \mathrm{pp}$

Hicks BB, Baldocchi DD, Meyers TP, Hosker RP, Matt DR (1987) A preliminary multiple resistance routine for deriving dry deposition velocities from measurement quantities. Water Air Soil Pollut 36:311-330

Kavanagh KL, Pangle R, Schotzko A (2007) Nocturnal transpiration causing disequilibrium between soil and stem predawn water potential in mixed conifer forests of Idaho. Tree Physiol 27:621-629

Kumar A, Chen F, Niyogi D, Manning K, Mitchell K, Ek M, Alfieri JG (2008) Integrating a photosynthesisbased canopy resistance model and satellite data in Noah land surface model. AMS. http://ams.confex. com/ams/pdfpapers/131425.pdf. Accessed 20 January 2008 
Lamaud E, Carrara A, Brunet Y, Lopez A, Druilhet A (2002) Ozone fluxes above and within a pine forest canopy in dry and wet conditions. Atmos Environ 36:77-88

Lui S, Mao D, Jia L (2007) Evaluating parameterizations of aerodynamic resistance to heat transfer using field measurements. Hydrol Earth Syst Sci 11:769-783

Mairgareth AC, Richards JH, Donovan LA (2007) Conductance and transpiration in C3 and C4 plants. Plant Physiol 143:4-10

Meyers TP, Finkelstein P, Clarke J, Ellestad TG, Sims PF (1998) A multilayer model for inferring dry deposition using standard meteorological measurements. J Geophys Res 103:645-661

Muller JF, Stavrakou T, Wallens S, Smedt ID, Roozendael MV, Potosnak MJ, Rinne J, Munger A, Goldstein A, Guenther AB (2008) Global isoprene emissions estimated using MEGAN, ECMWF analyses and a detailed canopy environment model. Atmos Chem Phys 8:1329-1341

Musselman CR, Minnick TJ (2000) Nocturnal stomata conductance and ambient air quality standards for ozone. Atmos Environ 34:719-733

Nikolov N, Massman W, Schoettle A (1995) Coupling biochemical and biophysical processes at the leaf level: an equilibrium photosynthesis model for leaves of C3 plants. Ecol Model 80:205-235

Niyogi D, Raman S (1997) Comparison of four different stomatal resistance schemes using FIFE observations. J Appl Meteorol 36:903-917

Niyogi D, Xue YK (2006) Soil moisture regulates the biological response of elevated atmospheric CO2 concentrations in a coupled atmosphere biosphere model. Glob Planet Chan 54:94-108

Niyogi D, Raman S, Alapaty K (1999) Uncertainty in specification of surface characteristics, part 2: hierarchy of interaction explicit statistical analysis. Boundary-Layer Meteorol 91:341-366

Niyogi D, Raman S, Alapaty K (2003) A photosynthesis-based dry deposition modelling approach. Water Air Soil Pollut 144:171-194

Niyogi D, Alapaty K, Phillips S, Aneja V (2006) Considering ecological formulations for estimating deposition velocity in air quality models. Int J Glob Environ 6:270-284

Niyogi D, Alapaty K, Raman S, Chen F (2009) Development and evaluation of a coupled photosynthesisbased gas exchange evapotranspiration model (GEM) for mesoscale weather forecasting applications. J Appl Meteorol Climatol 48:349-368

Noilhan J, Planton S (1989) A simple parameterization of land surface processes for meteorological models. Mon Weather Rev 117:536-549

Pleim JE, Xiu A (1995) Development and testing of a surface flux planertary boundary layer model with explicit soil moisture parameterization for applications in mesoscale models. J Appl Meteorol 34:16-32

Pleim JE, Finkelstein PL, Clarke JF, Ellestad TG (1999) A technique for estimating dry deposition velocities based on similarity with latent heat flux. Atmos Environ 33:2257-2268

Pleim JE, Xiu A, Finkelstein PL, Otte TL (2001) A coupled land-surface and dry deposition model and comparison to field measurements of surface heat, moisture, and ozone fluxes. Water Air Soil Pollut $1: 243-252$

Snyder KA, Richards JH, Donovan LA (2003) Night-time conductance in C3 and C4 species: do plants lose water at night? J Exp Bot 54:861-865

Turnipseed AA, Anderson DE, Blanken PD, Baugh WM, Monson RK (2003) Airflows and turbulent flux measurements in mountainous terrain: part 1 canopy and local effects. Agric For Meteorol 119:1-21

Turnipseed AA, Huey LG, Nemitz E, Stickel R, Higgs J, Tanner DJ, Slusher DL, Sparks JP, Flocke F, Guenther A (2006) Eddy covariance fluxes of peroxyacetylnitrates (PANs) and NOy to a coniferous forest. J Geophys Res 11:1-17

Turnipseed AA, Burns S, Moore D, Hu J, Guenther A, Monson R (2009) Controls over ozone deposition to a high elevation subalpine forest. Agric For Meteorol 149:1446-1459

Walmsley JL, Wesely ML (1996) Modification of coded parameterizations of surface resistances to gaseous dry deposition. Atmos Environ 30:1181-1188

Wesely ML (1989) Parameterization of surface resistance to gaseous dry deposition in regional scale numerical models. Atmos Environ 23:1293-1304

Wesely ML, Hicks BB (1977) Some factors that affect the deposition rates of sulfur dioxide and similar gases on vegetation. J Air Pollut Control Assoc 27:110-1116

Wu Y, John W, Donna S, Peters-Lidard C, Dennis R, Robarge W (2009) A new model of bi- directional ammonia exchange between the atmosphere and biosphere: ammonia stomatal compensation point. Agric For Meteorol 149:263-280

Zhang L, Brook JR, Vet R (2003) A revised parameterization for gaseous dry deposition in air quality models. Atmos Chem Phys 3:2067-2082 